\title{
Immunohistochemical Expression of Nanog and Its Relation with Clinicopathologic Characteristics in Breast Ductal Carcinoma
}

\author{
Omid Emadian Saravi ${ }^{1}$, Farshad Naghshvar ${ }^{2}$, Zhila Torabizadeh $^{2 *}$ and Somayeh Sheidaei ${ }^{1}$ \\ ${ }^{1}$ Department of Pathology, Faculty of Medicine, Mazandaran University of Medical Science, Sari, Iran; ${ }^{2}$ Department of \\ Pathology, Gastrointestinal Cancer Research Center, Mazandaran University of Medical Science, Sari, Iran
}

Received 12 March 2018; revised 14 July 2018; accepted 16 July 2018

\begin{abstract}
Background: Cancer stem cells (CSCs) are a group of tumor cells with self-renewal property and differentiation potential. CSCs play a crucial role in malignant progression of several types of tumors. However, what is still controversial is the clinicopathological relationship between the Nanog marker and its prognostic value in the patients with breast cancer. The expression of Nanog in the patients with breast cancer and its correlation with clinicopathological prognostic factors was explored in the present study. Methods: A sample of 120 breast cancer tissues was obtained from the patients who referred to Imam Khomeini Hospital in Sari City, Iran during January 2012 and December 2016. The associations between Nanog expression and clinicopathological factors were analyzed based on immunohistochemical analysis. Results: The expression of Nanog was detected in 67 (55.8\%) patients with a high expression rate in $24(36 \%)$ cases (staining index $\geq 3$ ). Moreover, there was a statistically significant relationship between Nanog expression and clinicopathological factors, including tumor grade $(p=$ $0.001)$, lymph node metastasis $(p=0.01)$, and the stage of the disease $(p=0.003)$. Conclusion: Findings of the study indicate that Nanog may act as a biomarker for prognostic prediction in patients with breast cancer. DOI: 10.29252/ibj.23.3.184
\end{abstract}

Keywords: Breast cancer, Immunohistochemistry, Nanog homeobox protein

\section{INTRODUCTION}

$\mathrm{B}$ reast carcinoma is the most common malignant tumor with the highest mortality rate in women. It involves more than 1.7 million cases around the world annually ${ }^{[1]}$. Despite improvements in cancer treatment, low overall survival rate is still found in patients with breast cancer. However, recurrence and distant metastasis after surgical resection of primary tumor are often incurable and fatal, leading to poor prognosis of breast cancer ${ }^{[2]}$. Cancer stem cells (CSCs) are potential players in the pathogenesis and development of malignant tumors, and this issue has been investigated by researchers in recent years ${ }^{[3,4]}$. CSCs are small populations of neoplastic cells within the tumor bulk with self-renew ability, which can create new tumors ${ }^{[5]}$. Currently, there is a consensus on the role of CSCs in progression, metastasis, and recurrence of various types of tumors ${ }^{[6,7]}$. Embryonic stem cells (ESC) have shown the same characteristics as the CSCs, which may indicate a similar mechanism in cancer development ${ }^{[8,9]}$. Dysregulated proliferation can be the underlying molecular mechanism of early embryo self-renewal reactivation ${ }^{[10]}$.

Nanog is a key multidomain homeobox transcription factor for maintaining ESC pluripotency ${ }^{[11,12]}$. Human Nanog gene is located on the chromosome region 12p13.31 and codes for a 305 amino-acid protein with conserved homeo-domain motif localized to the nucleus ${ }^{[13]}$. It has been known that Nanog acts in 
maintaining the undifferentiated state of pluripotent stem cells. The differentiation-promoting signals induced by the extrinsic factors, leukemia inhibitory factor/bone morphogenetic protein, leukemia inhibitory factor, and Stat3 are counteracted by Nanog expression $^{[14]}$. Nanog is a key protein that binds Rex-1 promoter and regulates the expression of this pluripotent marker. Nanog knockdown in ESCs leads to lower Rex-1 expression; however, forced expression of the protein induces Rex-1 expression ${ }^{[15]}$. The cell differentiation can be promoted when Nanog expression is down-regulated. Transcription factors Oct4, SOX2, FoxD3, and Tcf3 and tumor suppressor p53 contribute to the regulation of Nanog expression $^{[16]}$. Nanog is expressed in various types of malignancies, including brain tumors, breast cancer, and colorectal carcinoma ${ }^{[14]}$. The present study explored Nanog expression in patients with breast cancer and also its relationship with clinicopathological prognostic factors.

\section{MATERIALS AND METHODS}

\section{Sampling}

The specimens of breast cancers were obtained from 120 patients referred to Imam Khomeini Hospital in Sari (Iran) during January 2012 and December 2016. Clinicopathologic parameters were age, tumor size, histological grade, perineural invasion, vascular invasion, lymph node metastasis, and tumor stage. Data were gathered using hematoxylin and eosin (H\&E)-stained pathologic slides, pathological records, and hospital files. All the patients were women, with the mean age of 54.5 (ranging from 28 to 77) years. The samples were taken from the cancerous and adjacent normal tissues. For microscopic examination, the tissues were routinely fixed with formalin $10 \%$ before being embedded in paraffin.

\section{Ethical statement}

This research was performed using the samples stored after the pathological diagnosis. All the data were obtained from anonymous samples. Mazandaran University of Medical Science (Mazandaran, Iran) approved the study (ethical code: IR.mazums.rec. 95/1863).

\section{Inclusion and exclusion criteria}

Participants of the study included patients diagnosed with invasive ductal carcinoma following the breast surgery and those who did not receive neoadjuvant treatment. The inappropriate paraffin tissue blocks for immunohistochemical staining as well as those samples with incomplete documents were excluded from the study.

\section{Immunohistochemistry (IHC) procedure}

Tissue sections with 4 micrometer thickness were prepared and stained by $\mathrm{H} \& \mathrm{E}$ for histological evaluation, and representative blocks were chosen for immunohistochemical study. Absolute ethanol and $96 \%$ ethanol were used in three steps in order to eliminate paraffin-xylene solution. The slides were rinsed under running water, dried and transferred to $1 \%$ hydrogen peroxide mixture. Methanol was added to the target solution after $10 \mathrm{~min}$. In order to reach the boiling point, the slides were first transferred to autoclave with $100{ }^{\circ} \mathrm{C}$ for $13 \mathrm{~min}$ and then removed and put aside to reach room temperature. The tissue was washed with both running water and wash buffer. Next, the slides were incubated at envision for 60 minutes using diagnostic kit for monoclonal Nanog with 1/500 dilution, and then they were washed twice with wash buffer. The DAB solution was added and after appearing brown color, the slides were placed again in wash buffer for two minutes. Finally, the washed slides were stained with Mayer's hematoxylin, rinsed in distilled water, fixed in xylol and mounted with Entellan. Positive control kit for Nanog was Seminoma tissue. Our negative control was the tissue that the primary antibody did not shed. The nuclear staining was observed and scored by two pathologists according to the published criteria using a semiquantitative score ${ }^{[17]}$.

\section{Scoring}

For the evaluation of IHC results, the tumor cell staining intensity was measured using four scores as 0 (no staining), 1 (weak staining), 2 (moderate staining), and 3 (strong staining), as indicated in Figures 1a, 1b, $1 \mathrm{c}$, and 1d, respectively. Distribution of expression was also scored as 0 (none of tumor cells), 1 (1-50\% of positive tumor cells), and 2 (50-100\% of positive tumor cells). The total score was calculated by multiplying the percentage of cell staining by the staining intensity. Tumors with low and high expression had total scores of 0-2 and 3-5, respectively.

\section{Statistical analysis}

SPSS 22 was employed to analyze the data. Fisher's exact and chi-squared $\left(\mathrm{X}^{2}\right)$ tests were used to analyze the significance of the relationship between clinicopathological characteristics and Nanog expression. A $p$ value of less than 0.05 was considered as statistically significant. 


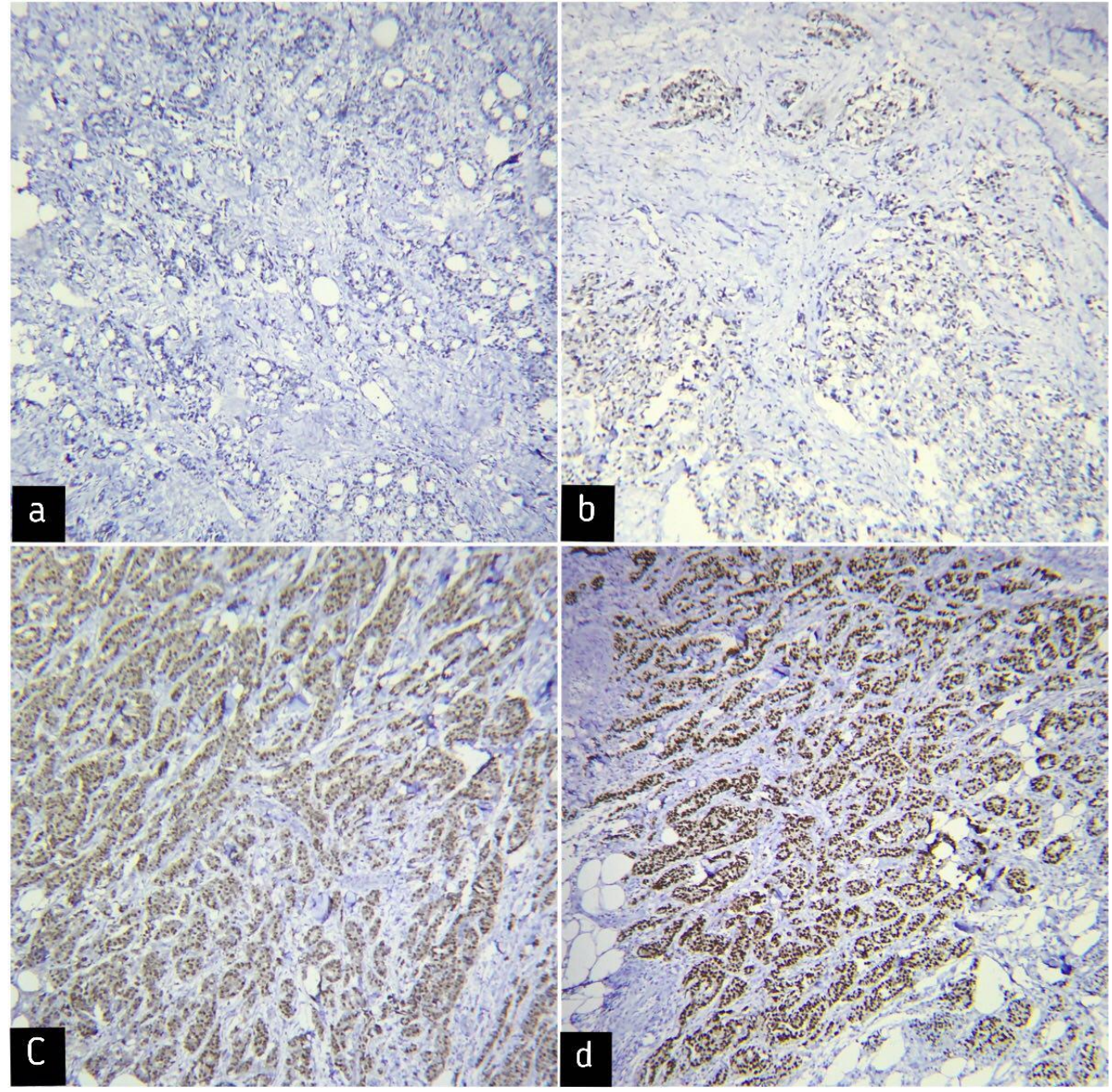

Fig. 1. Immunohistochemical staining of Nanog showing different expression levels in breast cancer samples (magnification $100 \times$ ). (a) Negative staining for Nanog (score 0), (b) weak staining for Nanog (score 1), (c) moderate staining for Nanog (score 2), and (d) severe staining for Nanog (score 3).

\section{RESULTS}

Samples of this study were 120 cases of invasive breast carcinomas. The mean age of the breast cancer patients was 54.5 at the time of their cancer diagnosis. The study detected Nanog by IHC staining in 67 samples of breast carcinomas $(55.8 \%)$. With regard to the degree of tumor differentiation, most of the cases were grade II (68 [56.7\%]), followed by $33(27.5 \%)$ as grade I and $19(15.8 \%)$ as grade III of the tumor. Sixtyseven of the breast cancer patients $(55.8 \%)$ of the study exhibited lymph node involvement. The higher Nanog expression was observed in 44 lymph node positive samples (36.7\%).

Table 1 briefly reports the association between clinicopathological parameters and the expression of Nanog. A significant correlation was found between Nanog expression and microscopic grade $(p=0.001)$, tumor stage $(p=0.003)$, and lymph node involvement
( $p=0.01)$ in breast cancer samples. There was not any relationship between Nanog expression and age $(p=0.71)$, tumor size $(p=0.25)$, perineural invasion $(p=0.06)$, and vascular invasion $(p=0.27)$.

\section{DISCUSSION}

In this study, $55.8 \%$ of tumoral sample have expressed Nanog marker. Finicelli et al. ${ }^{[18]}$ also reported Nanog expression in $44.5 \%$ of breast cancer patients that is close to our result. However, Nagata et al. ${ }^{[17]}$ found little (9.8\%) expression and Ezeh et al. ${ }^{[19]}$ observed no expression of Nanog in breast cancer cells. These differences in Nanog detection could result from different sensitivities of the methods used for assessing the Nanog expression. A number of studies have confirmed that Nanog is rather expressed in most patients with breast tumors compared to the individuals 
Table 1. Relationship between the expression of Nanog and clinicopathological factors

\begin{tabular}{|c|c|c|c|}
\hline Clinicopathological factors & $\begin{array}{l}\text { No. of positive } \\
\text { tumor cells (\%) }\end{array}$ & $\begin{array}{l}\text { No. of negative } \\
\text { tumor cells }(\%)\end{array}$ & $\begin{array}{c}p \\
\text { value }\end{array}$ \\
\hline \multicolumn{4}{|l|}{ Age (years) } \\
\hline $50<$ & $34(28.3)$ & $25(20.8)$ & \multirow[b]{2}{*}{0.717} \\
\hline $50 \geq$ & $33(27.5)$ & $28(23.3)$ & \\
\hline \multicolumn{4}{|l|}{ Tumor size } \\
\hline $2 \mathrm{~cm}<$ & $13(10.8)$ & $17(14.2)$ & \multirow{3}{*}{0.253} \\
\hline $2-5 \mathrm{~cm}$ & $40(33.3)$ & $25(20.8)$ & \\
\hline $5 \mathrm{~cm}>$ & $14(11.7)$ & $11(9.2)$ & \\
\hline \multicolumn{4}{|l|}{ Histological grade } \\
\hline 1 & $5(4.2)$ & $28(23.3)$ & \multirow{3}{*}{0.001} \\
\hline 2 & $51(42.5)$ & $17(14.2)$ & \\
\hline 3 & $11(6.7)$ & $8(6.7)$ & \\
\hline \multicolumn{4}{|l|}{ Perineural invasion } \\
\hline positive & $26(21.7)$ & $30(25)$ & \multirow{2}{*}{0.066} \\
\hline negative & $41(34.2)$ & $23(19.2)$ & \\
\hline \multicolumn{4}{|l|}{ Vascular invasion } \\
\hline positive & $35(29.2)$ & $22(18.3)$ & \multirow{2}{*}{0.273} \\
\hline negative & $32(26.7)$ & $31(25.8)$ & \\
\hline \multicolumn{4}{|l|}{ Nodal status } \\
\hline positive & $44(36.7)$ & $23(19.2)$ & \multirow{2}{*}{0.017} \\
\hline negative & $23(19.2)$ & $30(25)$ & \\
\hline \multicolumn{4}{|l|}{ Stage } \\
\hline 1 & $6(5)$ & $17(14.2)$ & \multirow{3}{*}{0.003} \\
\hline 2 & $26(21.7)$ & $20(16.7)$ & \\
\hline 3 & $35(29.2)$ & $16(13.3)$ & \\
\hline
\end{tabular}

with normal tissues ${ }^{[14,19]}$. In addition, its expression was linked to CSC-like properties ${ }^{[20]}$, tumor aggressiveness $^{[21]}$, hormone resistance ${ }^{[17]}$, and chemotherapeutic agents ${ }^{[22]}$.

We identified Nanog protein to be predominately expressed in the nucleus of tumor cells. IHC analysis of Nanog in breast carcinoma tissues has shown both nuclear and cytoplasmic localization of this protein; a result that is compatible with ours ${ }^{[17,19]}$. Our study also found a significant association between Nanog expression in tumor cells and several clinicopathologic factors. These factors included lymph node metastasis, stage of the disease, and histological grade. However, no relationship was detected between Nanog expression and age, tumor size, and neurovascular invasion. Finicelli et al. ${ }^{[18]}$ and Wang et al. ${ }^{[23]}$ have demonstrated a significant connection between tumor grade and Nanog expression in the majority of the patients who were diagnosed as grade II and grade III, respectively. We also obtained the same result but with patients in grade II. Similar to the findings of Ezeh et $a l .{ }^{[19]}$, we found a significant correlation between tumor, node, metastases stage 3 of the disease and the expression of Nanog marker. However, Nagata et al. ${ }^{[17]}$ and Wang et al. ${ }^{[23]}$ did not observed any link between the stage of the disease and Nanog expression ${ }^{[17,23]}$. With regard to the tumor size in our study, no significant correlation existed between Nanog expression and tumor size. Nevertheless, Wang et $a l .{ }^{[23]}$ have demonstrated a significant association between these two variables. It has been proposed that Nanog overexpression is related to resistance to hormone or anticancer therapy in breast cancer ${ }^{[20]}$. Arif et al.' $\mathrm{s}^{[24]}$ results showed that Nanog plays a role in tumorigenesis and affects the resistance to tamoxifen and has an inverse relationship with the expression of estrogen receptor and the apoptosis pathway. We showed that Nanog overexpression is clearly restricted to tumor cells, thus confirming the findings of Ezeh et al. ${ }^{[19]}$. In line with our study, Jin et al. ${ }^{[25]}$ and Wang et al. ${ }^{[23]}$ have revealed a significant correlation between the high expression of Nanog in breast cancer tissues and the higher rate of lymph node metastases. However, Finicelli et al. ${ }^{[18]}$ and Wang et al. ${ }^{[23]}$ did not find a significant relationship between Nanog expression and patients' age; this result was in agreement to our finding.

In this study, we found no significant link between 
perineural and vascular invasion. However, there is no study reporting these two prognostic factors. Nagata $e t$ $a l .{ }^{[26]}$ have shown that the overall survival was significantly low in breast cancer patients with Nanog overexpression, and thus the expression of Nanog might be a poor prognosis factor for all breast cancer subtypes. Finally, in a study by Finicelli et al. ${ }^{[18]}$, no significant correlation was found between Nanog expression and clinical outcome.

Some limitations of this study include short followup period, evaluation of distant metastasis, and survival rate of the patients. This study found a strong connection between Nanog expression and some clinicopathologic features in the patients with breast cancer, which includes lymph node metastasis, stage of the disease, and grade of disease. Our findings indicate that there is an association between the expression of Nanog and prognosis of the breast cancer patients. Moreover, worse prognostic characteristics were observed in the patients with high expression of Nanog. However, controversies exist among the studies conducted to evaluate this relationship.

\section{ACKNOWLEDGMENTS}

We thank Clinical Research Development Unit of Imam Khomeini Hospital, Mazandaran University of Medical Sciences, Sari, Iran for their financial support.

CONFLICT OF INTEREST. None declared.

\section{REFERENCES}

1. Begg CB, Ostrovnaya I, Geyer FC, Papanastasiou AD, Ng CKY, Sakr RA, Bernstein JL, Burke KA, King TA, Piscuoglio S, Mauguen A, Orlow I, Weigelt B, Seshan VE, Morrow M, Reis-Filho JS. Contralateral breast cancers: Independent cancers or metastases? International journal of cancer 2018; 142(2): 347-356.

2. Jemal A, Bray F, Center MM, Ferlay J, Ward E, Forman D. Global cancer statistics. CA: a cancer journal for clinicians 2011; 61(2): 69-90.

3. Bao B, Ahmad A, Azmi AS, Ali S, Sarkar FH. Overview of cancer stem cells (CSCs) and mechanisms of their regulation: implications for cancer therapy. Current protocols in pharmacology 2013; Chapter 14: Unit 14.25.

4. Liu S, Wicha MS. Targeting breast cancer stem cells. Journal of clinical oncology 2010; 28(25): 4006-4012.

5. Clevers $\mathrm{H}$. The cancer stem cell: premises, promises and challenges. Nature medicine 2011; 17(3): 313-319.

6. Ratajczak MZ. Cancer stem cells-normal stem cells "Jedi" that went over to the "dark side". Folia histochemica cytobiologica 2005; 43(4): 175-181.
7. Fábián A, Barok M, Vereb G, Szöllosi J. Die hard: are cancer stem cells the Bruce Willises of tumor biology? Cytometry A 2009; 75(1): 67-74.

8. Dick JE. Stem cell concepts renew cancer research. Blood 2008; 112(13): 4793-4807.

9. Reya T, Morrison SJ, Clarke MF, Weissman IL. Stem cells, cancer, and cancer stem cells. Nature 2001; 414(6859): 105-111.

10. Hart AH, Hartley L, Ibrahim M, Robb L. Identification, cloning and expression analysis of the pluripotency promoting Nanog genes in mouse and human. Developmental dynamics 2004; 230(1): 187-98.

11. Liu A, Yu X, Liu S. Pluripotency transcription factors and cancer stem cells: small genes make a big difference. Chinese journal of cancer 2013; 32(9): 483487.

12. Guo Y, Liu S, Wang P, Zhao S, Wang F, Bing L, Zhang Y, Ling EA, Gao J, Hao A. Expression profile of embryonic stem cell-associated genes Oct4, Sox2 and Nanog in human gliomas. Histopathology 2011; 59(4): 763-775.

13. Mitsui K, Tokuzawa Y, Itoh H, Segawa K, Murakami M, Takahashi K, Maruyama M, Maeda M, Yamanaka S. The homeoprotein Nanog is required for maintenance of pluripotency in mouse epiblast and ES cells. Cell 2003; 113(5): 631-642.

14. Jeter CR, Yang T, Wang J, Chao HP, Tang DG. Concise review: NANOG in cancer stem cells and tumor development: an update and outstanding questions. Stem cells 2015; 33(8): 2381-2390.

15. Shi W, Wang H, Pan G, Geng Y, Guo Y, Pei D. Regulation of the pluripotency marker Rex-1 by Nanog and Sox2. Journal of biological chemistry 2006; 281(33): 23319-23325.

16. Wong OG, Cheung AN. Stem cell transcription factor NANOG in cancers-is eternal youth a curse? Expert opinion therapeutic targets 2016; 20(4): 407-417.

17. Nagata T, Shimada Y, Sekine S, Hori R, Matsui K, Okumura T, Sawada S, Fukuoka J, Tsukada K. Prognostic significance of NANOG and KLF4 for breast cancer. Breast cancer 2014; 21(1): 96-101.

18. Finicelli M, Benedetti G, Squillaro T, Pistilli B, Marcellusi A, Mariani P, Santinelli A, Latini L, Galderisi U, Giordano A. Expression of stemness genes in primary breast cancer tissues: the role of SOX2 as a prognostic marker for detection of early recurrence. Oncotarget 2014; 5(20): 9678-9688.

19. Ezeh UI, Turek PJ, Reijo RA, Clark AT. Human embryonic stem cell genes OCT4, NANOG, STELLAR, and GDF3 are expressed in both seminoma and breast carcinoma. Cancer 2005; 104(10): 2255-2265.

20. Jeter CR, Liu B, Liu X, Chen X, Liu C, Calhoun-Davis T, Repass J, Zaehres H, Shen JJ, Tang DG. NANOG promotes cancer stem cell characteristics and prostate cancer resistance to androgen deprivation. Oncogene 2011; 30(36): 3833-3845.

21. Han J, Zhang F, Yu M, Zhao P, Ji W, Zhang H, Wu B, Wang Y, Niu R. RNA interference-mediated silencing of NANOG reduces cell proliferation and induces G0/G1 cell cycle arrest in breast cancer cells. Cancer 
letters 2012; 321(1): 80-88.

22. Huang ZJ, You J, Luo WY, Chen BS, Feng QZ, Wu BL, Jiang L, Luo Q. Reduced tumorigenicity and drug resistance through the downregulation of octamerbinding protein 4 and Nanog transcriptional factor expression in human breast stem cells. Molecular medicine reports 2015; 11(3): 1647-1654.

23. Wang D, Lu P, Zhang H, Luo M, Zhang X, Wei X, Gao J, Zhao Z, Liu C. Oct-4 and Nanog promote the epithelial-mesenchymal transition of breast cancer stem cells and are associated with poor prognosis in breast cancer patients. Oncotarget 2014; 5(21): 10803-10815.
24. Arif K, Hussain I, Rea C, El-Sheemy M. The role of Nanog expression in tamoxifen-resistant breast cancer cells. OncoTargets and therapy 2015; 8: 1327-1334.

25. Jin C, Zhang X, Sun M, Zhang Y, Zhang G, Wang B. Clinical implications of the coexpression of SRC1 and NANOG in HER-2-overexpressing breast cancers. OncoTargets and therapy 2016; 9: 5483-5488.

26. Nagata T, Shimada Y, Sekine S, Moriyama M, Hashimoto I, Matsui K, Okumura T, Hori T, Imura J, Tsukada K. KLF4 and NANOG are prognostic biomarkers for triple-negative breast cancer. Breast cancer 2017; 24(2): 326-335. 